\title{
Review \\ Distributed Leadership: A Scoping Review Mapping Current Empirical Research
}

\author{
Niamh Hickey*(1), Aishling Flaherty and Patricia Mannix McNamara $\mathbb{( 1 )}$ \\ School of Education, University of Limerick, V94 PX58 Limerick, Ireland; Aishling.Flaherty@ul.ie (A.F.); \\ Patricia.M.McNamara@ul.ie (P.M.M.) \\ * Correspondence: Niamh.Hickey@ul.ie
}

\begin{abstract}
Distributed leadership has enjoyed increased popularity, becoming a prevalent model of school leadership. The focus of distributed leadership is to foster shared leadership practices thereby enhancing school culture and practice. Despite multiple literature reviews that sought to yield greater understanding of the theoretical underpinnings of distributed leadership, there is little focus on empirical research on distributed leadership in post-primary schools. Therefore, this article reports on a scoping review of 39 empirical studies on distributed leadership in post-primary schools. The studies were analysed to identify the main trends of this body of research and to offer implications for future research. The main trends of this research corpus include the typical methodologies used, the common theoretical constructs which distributed leadership is studied in respect of, the most common distributed leadership theoretical framework subscribed to by research, and variances in understanding of distributed leadership. The authors offer future research implications for distributed leadership in post-primary schools. The results of this review lead us to conclude that there is a need for greater rigor in distributed leadership research. Future research is suggested regarding perceptions of distributed leadership, its relationship with policy, wellbeing, and female leadership, and the culture required for distributed leadership to flourish.
\end{abstract}

Keywords: distributed leadership; school leadership; post-primary schools; empirical research; scoping review

Leadership: A Scoping Review

Mapping Current Empirical Research.

Societies 2022, 12, 15. https:/ /

doi.org/10.3390/soc12010015

Academic Editor: Gregor Wolbring

Received: 16 December 2021

Accepted: 23 January 2022

Published: 26 January 2022

Publisher's Note: MDPI stays neutral with regard to jurisdictional claims in published maps and institutional affiliations.

Copyright: (c) 2022 by the authors. Licensee MDPI, Basel, Switzerland. This article is an open access article distributed under the terms and conditions of the Creative Commons Attribution (CC BY) license (https:// creativecommons.org/licenses/by/ $4.0 /)$.

\section{Introduction}

Discussion of distributed leadership in the context of organisation theory can be traced back to the mid 1960 's [1]. However, the construct shares similar characteristics with that of decentralised administration such as the spreading of responsibility and decision-making, which has been in the literature since the late $1800^{\prime} \mathrm{s}$ [2]. It was not long before distributed leadership began to take a foothold in the field of education with academics, school policy makers and school leaders soon commencing considerations of the potential implications of adopting distributed leadership models in schools [3]. Distributed leadership has now become prevalent and pervasive in both policy and practice spheres [4]. Distributed leadership is currently the most frequently adopted school leadership theory internationally $[5,6]$, and there has been a rapid increase in research on distributed leadership in schools in recent years [7]. While multiple literature reviews have sought to clarify the theoretical underpinnings of the distributed leadership construct, empirical research on the prevalence and influence of distributed leadership in post-primary schools has not been wholly reviewed. Therefore, this article provides a unique focus and valuable structure to the literature by reporting on a scoping review of empirical research on distributed leadership in post-primary schools between the years of 2009 and 2019.

\subsection{Blurred Definitions of Distributed Leadership}

Leadership has various meanings in different contexts [8], and distributed leadership does not offer any more clarity than the general nomenclature of leadership per se [9]. 
Distributed leadership has become so conceptually vast that it is difficult to distinguish between what signifies the construct and what does not [10]. There is little consensus with regard to various interpretations of what distributed leadership is, or what it looks like in schools [11]. Diamond and Spillane [12] suggest that conflicting opinions emerge between individuals who view distributed leadership as an attractive model, and those who simply equate the construct to other forms of shared leadership. The variety of definitions of the concept has led to conceptual ambiguity and the overlapping of constructs blurring the meaning of the term [13], even though distributed leadership has been reported to be a relatively easy concept to understand [14]. While it is inevitable that there is some discrepancy in conceptualisations of distributed leadership [12], given the inconsistences in definitions of leadership itself, these inconsistently and weakly defined core constructs are problematic, and lead to fuzzy research [15]. As a result, distributed leadership remains a largely elusive concept [1], whose chameleon-like nature allows it to be construed in numerous ways [13]. The variety in interpretations of distributed leadership has enabled theorists to "talk past each other" leading to common misunderstandings [4,16]. Furthermore, the field of educational leadership is known for being susceptible to investing in new theories with little proof of their benefits [1,17]. The reputation of the field creates unease regarding the uptake of new concepts and uncertainty relating to their true novelty [17]. This has resulted in conversations around distributed leadership as potentially being a case of "old wine in new bottles" [18] (p.144).

The nomenclature of distributed leadership has often been used synonymously with shared leadership and democratic leadership [18]. It has been misrepresented as a descriptor for all types of shared leadership and this has led to confusion and misunderstanding relating to distributed leadership as a concept [4,19]. In an attempt to avoid literature that does not fully do justice to the conceptualisation of a practice that has fast become central in education policy internationally, this review only considered research on "distributed leadership" as a stand-alone concept. This is in keeping with Spillane [18], who advocated for 'distributed leadership' to be discussed as a self-contained concept and should not be used synonymously with other terms.

The most universally accepted definition of distributed leadership illustrates it as a practice involving the interactions between leaders, followers and their environment with an emphasis on the importance of context [18]. Here, distributed leadership is based on the interactions between individuals and their environment such as organisational routines, structures and tools, rather than the sum of any individual's knowledge and skills [18]. It evolves from the activity of leadership itself rather than focussing on the role of any individual leader [20]. In a distributed model, leadership is "stretched" over an organisation, giving importance to the interplay between "leaders" as well as their individual actions [21]. Distributed leadership, as a model, does not aim to create more leaders per se, though that may be an unintended outcome, rather the focus is on creating better quality leadership [4].

As schools are increasing in complexity due to the increasing nature of their populations, the leadership skills of many rather than few are now required to succeed [4]. Distributed leadership has therefore become more prevalent within educational policy, with the UK, USA, Australia, New Zealand and parts of Europe advocating for its adoption in schools [1]. An increasing number of state agencies are encouraging the implementation of distributed leadership models [22]. An example of this in the United States of America is the State Action Leadership Projects (SAELP) funded by the Education Commission of the States, the Wallace Project and the Council of Chief State School Officers encouraging distributed leadership and teacher leadership [23]. The increased advocation for the adoption of distributed leadership is likely due to the problems associated with the traditional 'heroics of leadership' model in modern schools [18]. This traditional, heroic-style leadership is an individualistic approach to leadership based on the idea that leaders are superior to their followers [8]. It focuses solely on the actions of the leader (in this case the school principal), and neglects various other individuals and the tools and structures that are involved in 
leading successful schools [18]. This is in contrast to the shared and cooperative nature of distributed leadership which involves more than one individual being responsible for leadership duties.

\subsection{Previous Reviews and Positional Articles of Distributed Leadership}

Multiple reviews of literature and positional papers have sought to generate greater meaning of the theoretical underpinnings of the distributed leadership construct. Woods, et al. [24] published one of the earliest literature reviews in the field [7]. Reviewing literature between January 1996 and July 2002, the paper attempted to give "distinctiveness" to the topic [24]. Their review acknowledges that there are a variety of interpretations of distributed leadership and concludes that it has three distinctive characteristics; it is an emergent property, it opens the boundaries of leadership, and it is built on the idea that expertise is spread across many individuals in an organisation [24]. The positional paper written by Edwards [25] called for a more context-rich approach when debating the conceptualisation of distributed leadership, and a more critical focus in distributed leadership research [26-28]. Edwards [25] attempted to guide empirical research by outlining the elements that require consideration during these studies. These include symbolism, a sense of belonging, a sense of community, individualism, values and ethics, language, dialect and discourse, liminality and friendship [25]. In their historical review, Fitzsimons, James and Denyer [19] suggested areas requiring further research including, but not limited to, the influence of cultural values, task complexity, task interdependencies and competence; the influence of team size, and team diversity. They further challenged the existing conceptualisations of distributed leadership, while highlighting inconsistencies in research resulting in the conceptual confusion of shared and distributed leadership [19]. Bolden [27] concurred by stating that authors from the U.S. and U.K. each use the terms shared leadership and distributed leadership respectively, when discussing the same concept. Crawford [29] reviewed solo and distributed leadership literature in the Educational Management Administration and Leadership Journal over the past forty years to continue to grapple with the conceptualisation of distributed leadership. Building on the work of Bolden [27], Crawford [29] suggests a need to move away from one-dimensional views of distributed leadership to a hybrid model of leadership. This hybrid model would balance individual and shared leadership as well as highlight the importance of knowing which is more useful in a given context [27].

Exploratory factor analysis has been used in an attempt to sharpen the conceptualisation of the distributed leadership construct [30]. This study suggests that distributed leadership has four dimensions: bounded empowerment, developing leadership, shared decisions and collective engagement. The data and analysis of this study progressed knowledge in the field of distributed leadership; however, the use of raw scores through Likert style responses are not without their limitations [30]. The authors conclude by acknowledging that more research is required in the field to further tighten the concept of distributed leadership and the formation of more robust methodologies when researching distributed leadership [30].

Most recently Tian, et al. [31] reviewed distributed leadership literature between 2002 and 2013 and further investigated the gaps in the literature identified by Bennett, Wise, Woods and Harvey [11], including the failure to clarify distributed leadership and empirically define its application. Tian, Risku and Collin [31] concluded by noting the limitations of not having a universally accepted definition of distributed leadership is a major drawback. Lastly, Feng, et al. [32] sought to reimagine the construct by identifying four dimensions of distributed leadership; shared, conjoint, fragmented and dispersed. This study contributed significantly to the field by developing an analytical framework for distributed leadership, but acknowledges that it is limited, as reciprocal influences among variables is not considered in the study [32]. They concluded by re-emphasising that there has been little discussion regarding methodologies in previous literature, a gap that should be addressed in further research. Contrarily, Sivri and Beycioğlu [33] recently carried out a review of empirical research on distributed leadership in school settings and 
sought answers to specific questions through the use of content analysis. They examined articles in 10 international journals focussing on papers in primary and secondary school contexts and found there to be "no salient distribution model detected" [33] (p.158).

Many of the reviews and positional articles written on distributed leadership examine the theoretical conceptualisation of the theory. Woods, Bennett, Harvey and Wise [24] aimed to give the concept distinctiveness, and sixteen years later there is still no universally accepted definition. Youngs [7] has concluded that a universal definition is unlikely to eventuate due to the differing knowledge production positions evident with distributed leadership [34,35]. Hence, this scoping review contributed to moving away from a more exclusive focus on the theoretical and conceptual discrepancies of distributed leadership. Rather the aim is to map the current state of research regarding the empirical studies of distributed leadership in post-primary schools by identifying key trends and research implications. The review is unique in its focus on exploring the empirical studies of distributed leadership in post-primary school settings and in its structure of utilising a scoping review methodology to identify trends, limitations and directions for future research. The contribution of this review is that it will aid understanding of what is currently known about the concept, and cohere the knowledge by providing a synthesis of the literature in the field and points to areas of consensus that will aid researchers and practitioners. While the above reviews and positional articles outlined different understandings of distributed leadership, and some described various methodologies that best measure distributed leadership, these articles demonstrate the consensus that context and setting are integral to this understanding of distributed leadership. Therefore, the context and setting of the literature will underpin this review, including the cultural dynamics underlining the literature.

Due to the focus on theoretical conceptualisations of distributed leadership, less attention has been given to reviewing empirical research in the field. Discrepancies in the conceptualisation of distributed leadership has been noted amongst its researchers and theorists. This research was motivated by the aim to provide some clarity and coherence to the current literature with a focus on research from post-primary school teachers' and leaders' perspectives. The research question is thus conceptualised as "What is the current state of research in empirical studies of distributed leadership in post-primary schools?" A scoping review was chosen as the appropriate method of inquiry. Scoping reviews are a reasonably new approach to the synthesis of current evidence [36]. Their purpose is to give an overview of the current literature in a chosen field and to provide a cohering focus to the extant literature/evidence [37,38]. It is also a most favourable method for identifying and mapping key ideas of current literature in a given concept [36].

\section{Materials and Methods}

\subsection{Purpose and Structure of Review}

A scoping review can be defined as "a form of knowledge synthesis that addresses an exploratory research question aimed at mapping key concepts, types of evidence, and gaps in research related to a defined area or field by systematically searching, selecting, and synthesizing existing knowledge" [39] (pp. 1292-1294). A scoping review methodology was chosen over a systematic literature review as it is the optimal methodology to use when the interest lies in mapping the current literature and investigating the key ideas and characteristics of a concept [36]. However, like a systematic review, this scoping review utilised "comprehensive and structured searches of the literature" [40] (416). Scoping reviews aim to synopsize and disseminate findings as well as identify current gaps in the literature [38]. This review aims to map the current state of research in empirical studies of distributed leadership in post-primary schools by identifying trends and research implications.

This methodology was outlined prior to analysis in a registered protocol available at Open Science Framework, DOI 10.17605/OSF.IO/P8HF4. The reviewers implemented the framework of Arksey and O'Malley [38], who propose that there are six stages involved in conducting a scoping review. 
1. Identifying the research question;

2. Identifying relevant studies;

3. Study selection;

4. Charting the data;

5. Collating, summarising and reporting the results;

6. Consultation exercise

Stage 1 involved identifying the research question. In this case the authors followed the Participants, Interest and Context (PICo) framework. This mnemonic is used to guide researchers to identify their research question for a qualitative review [41]. The PICo step yielded the following research question: "What is the current state of research in empirical studies of distributed leadership in post-primary schools?"

Stage 2 involved identifying relevant studies in the existing databases. The search for literature mirrored that of a systematic literature review [40]. First, the researcher consulted with a university librarian to ensure all relevant online databases were identified and included. The utilization of online databases has been argued to be the most important method of identifying articles [42]. Table 1 illustrates the databases that were searched to identify relevant studies as well as the additional databases searched to ensure that no similar reviews are currently registered.

Table 1. Selected Databases.

\begin{tabular}{ccc}
\hline Main Databases & Grey Literature & Ensure Novelty \\
\hline & Dissertations \& Theses A\&I, & \\
Education Source, Education & Dissertations \& Theses: UK \& & PROSPERO, \\
Source (full text), ERIC & Ireland, & Joanna Brigg's Institute, \\
(EBSCO), ERIC ProQuest, & Campbell Collaboration, & Cochrane, \\
SCOPUS & DART Europe E-Thesis and & Figshare, \\
& Portal, & Open Science Framework \\
& Google Scholar & \\
\hline
\end{tabular}

Google Scholar was used as a backup 'catch all' to the traditional search methods employed. The first 200 results on Google Scholar were considered for inclusion as suggested by Haddaway, et al. [43]. The reference lists of the studies identified from online searches were also included in the search to ensure that all literature relating to the topic was located [38-40].

A general search string was created by the researchers in conjunction with the university librarian, which was adapted for each individual database. An example of the search string for the database Education Source can be found in Appendix A.

\subsection{Types of Study to Be Included}

Stage 3 comprised study selection. All types of articles, literature from any/all countries of a qualitative or quantitative nature are eligible for inclusion in this review. A timeframe of 10 years (2009-2019), which is outlined as the maximum timeframe for literature reviews [44], was employed in the search strategy. Literature must have had a linked full text, been available in English and take the form of either a peer-reviewed text or thesis to warrant inclusion. Articles must have referred to the term "distributed leadership" as a stand-alone concept and have not used other terms such as "shared leadership" as the assumption adopted for conceptual clarity was that they were not synonymous [18]. Finally, only empirical studies that directly collected data from teachers and leaders were eligible for inclusion.

Based upon these steps the search identified a total of 196 articles for potential inclusion, which were then tested against an inclusion and exclusion criteria. Inclusion and exclusion criteria were developed based on the research question [45]. Table 2 details these criteria. 
Table 2. Inclusion and exclusion criteria.

\begin{tabular}{|c|c|}
\hline Inclusion & Exclusion \\
\hline Studies published between 2009 and 2019 & Studies published before 2009 \\
\hline Studies written in English & Studies not written in English \\
\hline Studies with linked full texts & Studies without linked full texts \\
\hline $\begin{array}{l}\text { Studies discussing teachers' and leaders' } \\
\text { (Principal, Deputy Principal, Assistant } \\
\text { Principals, Head of Department) perceptions of } \\
\text { distributed leadership in post-primary schools } \\
\text { (middle schools, high schools, junior high } \\
\text { schools, secondary schools). }\end{array}$ & $\begin{array}{l}\text { Studies discussing the perceptions of those } \\
\text { other than teachers or leaders } \\
\text { (parents/students etc.). }\end{array}$ \\
\hline $\begin{array}{l}\text { Studies discussing distributed leadership as a } \\
\text { singular form of leadership. }\end{array}$ & $\begin{array}{l}\text { Studies discussing alternative forms of } \\
\text { leadership (e.g., student leadership, teacher } \\
\text { leadership etc.) or mixed leadership styles. }\end{array}$ \\
\hline Quantitative and/or qualitative research & $\begin{array}{c}\text { Studies discussing distributed leadership in a } \\
\text { non-education-based setting or } \\
\text { education-based settings other than } \\
\text { post-primary schools (elementary schools, } \\
\text { primary schools, third level education etc.). }\end{array}$ \\
\hline Empirical research & Non-empirical research \\
\hline Peer-reviewed literature or theses & Non-peer reviewed literature excluding theses \\
\hline
\end{tabular}

A total of 157 articles were excluded when tested against the inclusion and exclusion criteria. The primary reasons for the exclusion of these papers were that they were not specific to post-primary schools or that they discussed forms of leadership other than distributed leadership. A risk of bias (quality) assessment was then employed on the remaining 39 papers.

While it is generally not recommended to appraise the quality of literature in a scoping review [38], the researchers added quality appraisal to the Arksey and O'Malley [38] framework. This is proposed when a scoping review is written with the intention of publication [46]. Crowe's Critical Appraisal Tool (CCAT) was chosen for implementation. This tool consists of a form accompanied by a user guide, which should be used in unison to reliably assess the literature and assist in consequent inclusion and exclusion [47].

Of the 39 articles, none were excluded from the review following the application of the CCAT. Figure 1 below illustrates the study selection process through the a PRISMA flow chart [48]:

Stage 4 comprised charting the data. Charting is a process for interpreting qualitative research involving the "lifting" and rearranging of data into themes [49]. The data lifted in this review, to map the current state of research in empirical studies of distributed leadership in post-primary schools can be seen in Table 3. 


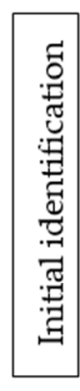

Articles identified through searches of online databases.

$(\mathrm{n}=187)$
Additional articles found from scanning paper references (and passed criteria)

$(\mathrm{n}=46)$

\section{No linked full text $(\mathrm{n}=2)$}

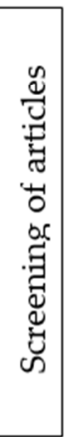

Articles remaining after duplicates removed.

$(n=196)$
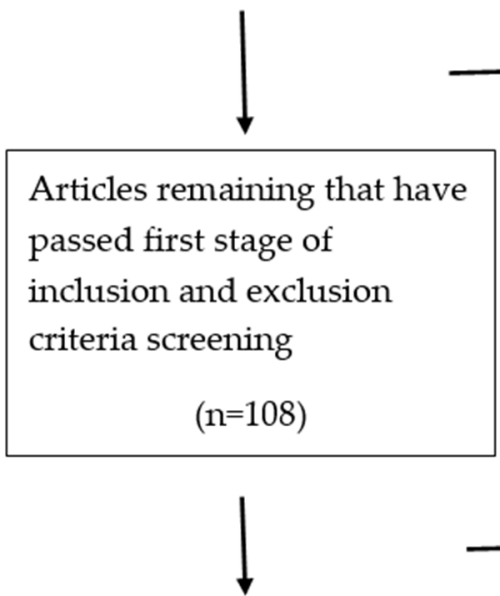

Articles remaining before completion of CCAT application. $(\mathrm{n}=39)$

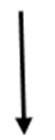

Articles to be included in the literature review.

$(\mathrm{n}=39)$
Duplicates removed $(\mathrm{n}=35)$

Articles excluded after inclusion and exclusion criteria screening of title and abstract

$(\mathrm{n}=88)$

Articles excluded after inclusion and exclusion criteria screening of full text

$$
(\mathrm{n}=69)
$$

Full text articles excluded due to quality or other reason

$$
(\mathrm{n}=0)
$$

Figure 1. PRISMA Flow Chart. 
Table 3. Data Lifted During Charting Process.

\begin{tabular}{|c|c|}
\hline Publication Details & $\begin{array}{l}\text { Citation } \\
\text { Publication type }\end{array}$ \\
\hline Study Characteristics & $\begin{array}{l}\text { Aim/Objectives of the study } \\
\text { Methodology } \\
\text { Scale used (if applicable) } \\
\text { Topic investigated in conjunction with teachers' } \\
\text { and leaders' perceptions of distributed } \\
\text { leadership (if applicable) }\end{array}$ \\
\hline Participants & Teachers/leaders/teachers and leaders \\
\hline Conceptualisations of Distributed Leadership & $\begin{array}{l}\text { Positive/neutral/negative perceptions of } \\
\text { distributed leadership } \\
\text { Author's conceptualisation (if identified) } \\
\text { Participant's conceptualisation (if identified) } \\
\text { Consistency of author to participant } \\
\text { conceptualisation } \\
\text { Were measures taken to limit discrepancies in } \\
\text { interpretations (if so, what were they?) }\end{array}$ \\
\hline Limitations & $\begin{array}{l}\text { Are conceptualisation issues noted as a } \\
\text { limitation? }\end{array}$ \\
\hline
\end{tabular}

Stage 5 comprised collating, summarizing and reporting the results.

The data were analysed in two phases. Initially, the researchers charted and graphed the research methods trends. Then, the data were analysed thematically to identify implications for the research.

The final optional stage regarding the use of a "consultation exercise" [38] was not implemented in this review as it was not deemed valid.

\subsection{Limitations of This Scoping Review}

There are some limitations to this review. The review was limited to research on distributed leadership as a stand-alone concept. Literature examining shared leadership, teacher leadership or any other related concept were not included in the study. While this ensured the integrity of the concept, it may also have resulted in a loss of potentially relevant studies as some authors use the terms interchangeably. Secondly, the review was limited to primary research of an empirical nature, resulting in the exclusion of conceptual papers and literature reviews which may have provided additional information.

\section{Results}

The findings section of this review maps the emerging trends within empirical distributed leadership research in post-primary schools. It provides an overview of the research that has been conducted from 2009 to 2019. These findings include trends among the research methods used, the relationships between distributed leadership and various other constructs, and the conceptualisations of distributed leadership that underpin the body of research.

\subsection{Trend 1: Research Methods_Distributed Leadership Studies Used a Variety of Methodologies in Various Contexts}

\subsubsection{Geographical Considerations}

This scoping review yielded a total of 39 papers which were conducted in a number of different countries. The majority of studies were carried out in the United States of America $(30.8 \%, N=12)$, followed by Belgium $(20.5 \%, N=8)$. The remaining studies were conducted in a number of countries in lesser frequency. See Table 4. 
Table 4. Geographical location of studies.

\begin{tabular}{ccc}
\hline Country & $\begin{array}{c}\text { Percentage of Studies } \\
\text { Conducted (\%) }\end{array}$ & $\begin{array}{c}\text { Number of Studies } \\
\text { Conducted (N) }\end{array}$ \\
\hline United States of America & 30.8 & 12 \\
\hline Belgium & 20.5 & 8 \\
\hline Bangladesh & 7.7 & 2 \\
\hline Turkey & 5.1 & 2 \\
\hline Ireland & 5.1 & 1 \\
\hline Egypt and Oman & 2.6 & 1 \\
\hline Finland and Shanghai & 2.6 & 1 \\
\hline Saudi Arabia & 2.6 & 1 \\
\hline Cyprus & 2.6 & 1 \\
\hline Hong Kong & 2.6 & 1 \\
\hline England & 2.6 & 1 \\
\hline Nigeria & 2.6 & 1 \\
\hline Ghana & 2.6 & 1 \\
\hline Iran & 2.6 & 1 \\
\hline South Africa & 2.6 & 1 \\
\hline Slovenia & 2.6 & 2.6 \\
\hline New Zealand & & 1 \\
\hline
\end{tabular}

\subsubsection{Research Designs}

The 39 studies included in the review were either quantitative $(35.9 \%, N=14)$, mixed methods $(33.3 \%, N=13)$, or qualitative $(30.8 \%, N=12)$ in nature. The statistics show a relatively equal distribution of the different research designs. The most common research design chosen was a case study design with $33.3 \%(N=13)$ of studies using this approach. See Table 5 for further details of the methodologies used in the studies.

Table 5. Research design of studies.

\begin{tabular}{ccc}
\hline Research Design & $\begin{array}{c}\text { Percentage of Studies } \\
\text { Conducted (\%) }\end{array}$ & $\begin{array}{c}\text { Number of Studies } \\
\text { Conducted }(\boldsymbol{N})\end{array}$ \\
\hline Case Study & 33 & 13 \\
\hline Quantitative & 15.4 & 4 \\
\hline Mixed Methods & 10.2 & 3 \\
\hline Correlation Research Model & 7.7 & 2 \\
\hline Qualitative & 5.1 & 2 \\
\hline Multilevel Approach & 5.1 & 2 \\
\hline Descriptive Survey Method & 5.1 & 1 \\
\hline Phenomenological & 2.6 & 1 \\
\hline Explanatory Sequential Mixed-Method & 2.6 & 1 \\
\hline design & 2.6 & 1 \\
\hline Developmental & 2.6 & 1 \\
\hline Ulongsider" Research Methodology & 2.6 & 1 \\
\hline Q & 2.6 & 1 \\
\hline
\end{tabular}




\subsubsection{Study Populations}

The majority of studies included insights from both teachers and school leaders $(61.5 \%$, $N=24)$. Fewer numbers of studies chose a population of just teachers $(20.5 \%, N=8)$ or school leaders on their own $(17.9 \%, N=7)$. Other study participants which appeared less frequently included Department Chairs, Central Office Administrators, Teacher Union Representatives, as well as an official of the Royal Patron Project.

\subsection{Trend 2: Relationships-Distributed Leadership Studies were Related to Multiple Constructs}

Many studies in this review examined distributed leadership as the sole focus of the research $(30.8 \%, N=12)$. The remaining studies investigated distributed leadership in relation to another construct $(69.2 \%, N=27)$. These constructs are composed of theoretical frameworks, characteristics of leadership or features of a school which were studied alongside distributed leadership. The construct investigated most frequently alongside distributed leadership was found to be organisational commitment $(15.4 \%, N=6)$, followed by school improvement $(10.2 \%, N=4)$. Other constructs include female leadership, teaching capacity, job satisfaction etc. See Figure 2 for more details.

\subsubsection{Organisational Commitment}

Organisation commitment is defined as the "relative strength of an individual's identification with and involvement in a particular organization" [50] (226). The relationship between distributed leadership and organisational commitment was the focus of six (15.4\%) of the articles included in this review. The majority of these studies were quantitative in nature $(12.8 \%, N=5)$, while one study used a qualitative approach $(2.6 \%, N=1)$.

These studies support the idea that teachers' organisational commitment is positively influenced by the cooperation of the leadership team as well as participative decision making [51-56]. The cooperation of the leadership team, characterised by role clarity, goal orientedness and group cohesion [51,52,54-56], as well as teachers' participation in decision-making, are central characteristics of distributed leadership. This suggests a positive relationship between distributed leadership and organisational commitment.

\subsubsection{School Improvement}

The second most frequent construct investigated in relation to distributed leadership was that of school improvement $(10.2 \%, N=4)$. All four studies suggest that the interactions between distributed leadership and school improvement are positive [57-60]. Kelley and Dikkers [59] evidenced this link through the medium of feedback. Distributed leadership helped to overcome the limitations of evaluation feedback, therefore positively influencing school improvement. Bird [57] suggested a positive link between distributed leadership and school improvement through the responses of senior managers and heads of departments in a focus group setting. This was based on the idea that support lends itself to willingness to work which in turn makes a school a better place [57].

Furthermore, questionnaires asking teachers about the importance of conditions associated with distributed leadership and school improvement suggest that participative decision-making and creating favourable conditions to support team leadership were deemed the most important [58]. Finally, Obadara [60] used a descriptive survey design to determine that there is a significant relationship between distributed leadership and school goal achievement, the professional development of teachers, instructional program management, effective teaching and learning, and promotion of school climate.

\subsubsection{Other Constructs}

Female leadership is a topic that requires significant attention as female teachers comprise $68 \%$ of all teachers, however, they comprise just $45 \%$ of principal positions, as of the last available data in 2013 [61], later referenced by Martínez, et al. [62]. This has been investigated in conjunction with distributed leadership twice over the past ten years (5.1\%) according to the literature in this review. The first of these studies aimed to examine female 
leaders' perceptions of the Tatweer System in Saudi Arabia [63]. Findings of this qualitative study suggest that the Tatweer System is "semi-decentralised" and breakthroughs have taken place at a local level in relation to distributed leadership within these female-led schools [63].

The second study aimed to compare data gathered from female post-primary school principals in Texas in 1998 with data gathered in 2011 to identify changes in personal, professional, leadership and school characteristics. This study found that while there was no significant change to the overall number of females in principal roles, women in these roles were becoming more diverse, and entering principalship at a younger age [64]. It was also found that women's scores on distributed leadership were high [64]. However, it is difficult to draw conclusions from two studies that had different focuses. Other constructs that appeared in lesser frequency include self-efficacy, sensemaking and newly qualified teacher (NQT) induction. For a full account of topics studied in relation to distributed leadership see Figure 2.

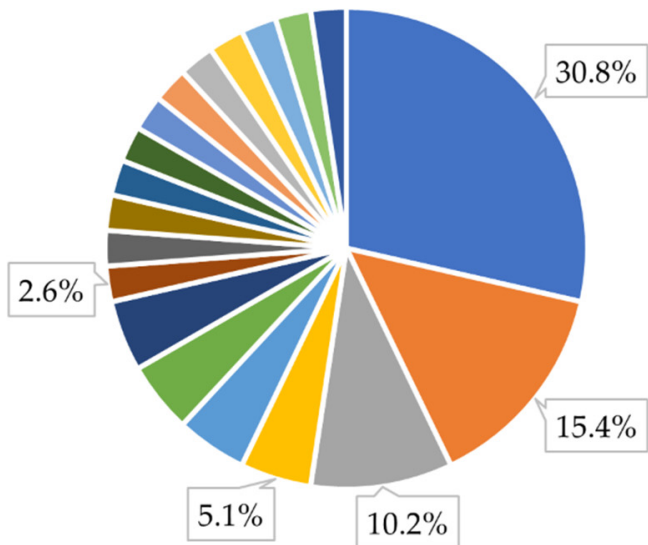

- No additional construct $(30.8 \%)$

n Organisational Commitment (15.4\%)

- School Improvement (10.2\%)

- Female Leaders (5.1\%)

- Self-efficacy $(5.1 \%)$

- Job Satisfaction (5.1\%)

- Trust $(5.1 \%)$

- Psychological Contracts (2.6\%)

- Teaching Capacity (2.6\%)

n NQT Induction (2.6\%)

• School Culture $(2.6 \%)$

- Work Redesign $(2.6 \%)$

- Impact on Teaching and Learning (2.6\%)

n Turnaround Status and Sustainability (2.6\%)

n School Effectiveness (2.6\%)

Decentralisation (2.6\%)

- Role of principal in fostering DL $(2.6 \%)$

- Democratic Leadership (2.6\%)

- Sensemaking $(2.6 \%)$

Figure 2. Constructs studied in conjunction with distributed leadership.

3.3. Trend 3: Conceptualisations Underpinning Studies-The Prevalence of Spillane's Distributed Leadership Theory

Eighty two percent of studies reviewed $(N=32)$ were underpinned to some extent by the distributed leadership theoretical framework set out by Spillane [65]. This is to be expected as Spillane and his colleagues were heavily involved in developing the central conceptual model of distributed leadership [19]. Within these studies, distributed leadership is outlined as a set of functions that are carried out by a group of people rather than an individual. Distributed leadership provides a space for both formal and informal leaders within the school community $[66,67]$. The 'leader plus' strategy which acknowledges the importance of multiple leaders, routines and structures [65], became apparent 
on reading the literature outlining that multiple individuals take responsibility for school leadership. This concept was built upon as Spillane [65] was cited in his acknowledgement of distributed leadership as the convergence of leaders, followers and situations.

Several articles were anchored by the understanding that distributed leadership is characterised by the dynamic interactions between these three groups rather than the sum of individuals' actions [57,59,68-70]. Distributed leadership was conceptualised as "stretching" over the entire school community, with the focus of leadership practice taking centre stage rather than the individuals who are responsible for any given task. This not only suggests that leadership arises from a number of individuals rather than one solo leader, but it also stems from their interactions between these individuals, and with their situation. Context is therefore integral to this research. Spillane [65] has a descriptive approach to distributed leadership, while many other researchers approach the topic in a normative manner [27]. Both of these approaches have been critiqued as limited, as other scholars advocate for a critical perspective [28]. It is noteworthy that researchers continue to align their work with Spillane [65] and a largely descriptive approach.

In contrast to this, the remaining eighteen percent of studies $(N=7)$ measured distributed leadership in relation to just formal leaders in the school. This consisted of the principal, assistant principal and teacher leaders. When discussing distributed leadership, the authors accounted for the actions of this group known as the "leadership team" [51-54,71,72].

\subsection{Trend 4: Conceptualisations of Participants-Discrepancies in Participants' Understandings of Distributed Leadership}

Throughout the reviewed studies, it was common for research participants to have different perceptions of what distributed leadership is and how it may look in a particular setting. The idea that distributed leadership equates to the delegation of tasks is a common misconception that exposed itself during the review which does not align with the theoretical underpinning of the studies $[67,70,73,74]$. Distributed leadership should not be confused with either delegation or devolution [73-75]. Some individuals in the reviewed studies had simply never heard of the concept before and therefore, had not conceptualised it internally $[57,67]$.

Other research participants were conscious that their school principal was creating an awareness that all teachers are leaders, but were not sure if everyone knew why they were doing so [76]. They understood that they all had a role as leaders within the school but did not necessarily realise that they were enacting distributed leadership [76]. This suggests that some participants may not have internally conceived the concept of distributed leadership prior to participating in a study seeking to gain insight into the influences of distributed leadership. This ambiguity infers concern regarding the validity of research seeking to explore the influence of distributed leadership without due consideration being given to standardising perceptions, and understandings of the nature of the construct first. Nevertheless, it is noted that some ambiguity is to be expected given the elusiveness of the distributed leadership concept [1].

\section{Implications}

The findings of this review can offer implications and directions for future research on distributed leadership in post-primary school settings. We conclude from the findings that there is a need for greater rigour to be demonstrated in distributed leadership research. There is also a need for researchers to consider additional approaches to studying distributed leadership in post-primary schools.

\subsection{Rigour}

\subsubsection{Consideration of Policy and Context}

The research methods used throughout the studies included in this review vary considerably, but few studies have considered how the context in which the research took 
place could have influenced the findings of this research. Context is fundamental to making meaning from complicated tasks [19]. Ideas that are external to a school such as policy can act as a stimulus for rethinking leadership practices [24]. The structure and context of a school is so intertwined with its leadership practice that it has been described as impossible to study one without the other [24]. Leadership and organisational culture have a reciprocal dynamic that must be considered when researching the topic. Several studies included in this review appear to have investigated distributed leadership practice without due consideration given to the school context or school policy. It is imperative for future research to consider how the school context or school policy could influence the dimension of distributed leadership being investigated.

While it is important to note that many of these studies were conducted in AngloAmerican countries, many studies included in this literature review vary significantly in context and culture and it remains unclear if these contextual factors had an impact on the findings as context did not form part of the analysis. For example, Hasanvand, et al. [77] outline the relationship between distributed leadership and principals' selfefficacy in Iran. At this time distributed leadership had received little attention in Iran and leadership equated with authority and position [78]. In contrast to this, a study in this review was conducted in South Africa [67] where the Policy for South African Standard for Principalship may not endorse distributed leadership per se but recommends empowering those in the school community and engaging in participative decision-making. It is reasonable to suggest that these policy contexts may influence adoption or lack thereof of leadership models. At the very least they are a contextual factor that warrant exploration. The impact of policy on these studies could be influential to their perceptions and adoption of distributed leadership, but this remains unclear as results are currently presented.

Other external factors which may have the potential to influence the uptake and enactment of distributed leadership are school evaluation guidelines, parental involvement, school type and size, which also have not been considered by research at length. Spillane [18] emphasises the importance of 'situation' regarding distributed leadership implementation, yet attention to 'situation' is largely overlooked in distributed leadership research of the last ten years. This review reveals some ambiguity, some challenges and the potential for increased workload and stress as a result of uncritical implementation of distributed leadership practices. We recommend that both national and school policy should be considered in all distributed leadership studies as context and culture may impact the implementation of distributed leadership, to some considerable degree as has been the case in Ireland, for example.

\subsubsection{Reproduction and Verification of Research}

The quantity and methodology of distributed leadership research has appeared to develop significantly within the past ten years [31], but the field has also been critiqued for lacking methodological rigour [30]. Distributed leadership has been recognised as having a positive impact on organisational commitment [51-56] and school improvement [57-60].

Simple correlational relationships have been noted between distributed leadership and school improvement. A discrete positive relationship between the two has not yet been proven. Four studies investigating the relationship between distributed leadership and school improvement were carried out in England, Ghana, United States of America and Nigeria, each using various research designs. All four studies suggest that there are positive interactions between distributed leadership and school improvement. However, mediums of feedback [59], willingness to work [57], participation in decision making and creating favourable conditions [58] were used to bridge the gap between distributed leadership and school improvement, rather than illustrating a direct link between the two. A gap in the literature remains regarding evidence of the linkage between distributed leadership and school improvement within post-primary schools. A causational relationship is worthy of investigation. 
The six studies investigating the relationship between distributed leadership and organisational commitment are written by the same authors, drawing inferences from similar contexts and cultures [51-56]. All six of these papers are based on research conducted in Belgium, many of which use similar quantitative research approaches. The research also illustrates the positive relationship between organisational commitment and two traits associated with distributed leadership (cooperation of the leadership team and participative decision-making), rather than distributed leadership as an entire construct. Causational relationships directly linking distributed leadership and organisational commitment remain unexplored. Further research is necessary to inform conclusions regarding the relationship between distributed leadership and organisational commitment. Qualitative research in this area is particularly lacking. An exploratory mixed-methods study, and perhaps longitudinal studies, may provide greater insight into the relationship that is thus far limited in geographical location and methodology. Research examining distributed leadership and female leaders also requires further investigation as self-reporting tools were used to detect changes in personal, professional, leadership, and school characteristics [64]. This study, along with others using self-reporting tools, are limited in their approach and are widely criticised [79].

Further studies investigating the relationship between distributed leadership and organisational commitment, school improvement and female leadership are required to advance the field. Studies investigating organisational commitment, are limited in their approach and geographical scope. The studies examining school improvement suggest a link using characteristics of distributed leadership such as willingness to work [57], and participation in decision making and creating favourable conditions [58], rather than proving a direct link between school improvement and distributed leadership. The studies are correlational rather than causal. Female leadership was investigated with distributed leadership twice, and one of these studies used a self-reporting tool which are often critiqued on the basis of validity of studies [79]. Replicable research of greater rigour is required to determine the link between distributed leadership and organisational commitment and school improvement. Further investigation of this nature is also required regarding distributed leadership and other lesser-explored concepts such as job satisfaction, teaching capacity and sense-making (See Figure 2). Future studies must ensure greater methodological rigour and replication in order to advance the field.

\subsubsection{Conceptualisations of Distributed Leadership}

None of the 39 studies in this review investigated the impact that differing conceptualisations may have had on their study or expressed how they attempted to avoid misinterpretations of the concept. Furthermore, little research has been conducted to examine the pattern between teachers' vs. school leaders' interpretations to inform researchers during data sampling and analysis. Not all studies used the nomenclature of distributed leadership and some studies explicitly asked participants for their understandings of distributed leadership during interviews or part of questionnaires. However, these variances limit data analysis as researchers are required to consider each individual's conceptualisation which they may or may not have received in sufficient detail.

While we acknowledge that distributed leadership will take on a variety of meanings in differing context and cultures, the reliability and validity of research analysing the influence of distributed leadership may be impacted if research participants do not have a shared understanding of distributed leadership prior to participating in such research. In order to avoid this and establish a standardised measure to base assessment off, it is recommended that all participants are provided with a clearly defined conceptualisation of distributed leadership prior to participating in the research. It is unclear if this potential discrepancy was considered in the studies as this limitation was noted in only one research paper [80]. Salahuddin [80] acknowledged the potential discrepancy in conceptualisations by stating that the study was limited by the restrictions of principals' conceptualisation 
and use of the phrase 'distributed leadership'. Greater consideration of such potential discrepancy is required when researching concepts such as distributed leadership.

When investigating a concept such as distributed leadership, which means different things to different people, it is unclear if the discrepancy in perceptions impact data collection. None of the studies in this review explain how they ensured clarity regarding the perception of 'distributed leadership' that they were using for the purpose of their study, or how they ensured consistency in perceptions. If participants do not perceive distributed leadership to mean the same thing, it is difficult to draw informed conclusions from the data. The field of distributed leadership requires investigation of the impact that discrepancies in perceptions can have during data collection. Future studies of the concept can benefit from these findings by investigating distributed leadership in a way that ensures more robust, valid, and reliable data collection.

\subsection{Future Directions for Research}

\subsubsection{Exploration of the Culture Needed for Distributed Leadership to Flourish}

The first recommendation for future research is an exploration to understand how school culture can improve the adoption of distributed leadership in post-primary schools. School culture and school leadership are inextricably linked [81]. The culture of a school can be a significant factor in resistance to reforms and policies [82]. Research has yet to extensively consider cultural influences on distributed leadership in post-primary schools. This relationship has only been studied once within empirical research in post-primary schools in the past decade. Without researching the intersection between school culture and distributed leadership, the conditions required for distributed leadership to flourish are currently unknown.

\subsubsection{Investigation of the Relationship between Distributed Leadership and Policy}

The second recommendation of this review is an investigation of the influence that national policy on distributed leadership may have on leadership practice in post-primary schools. Distributed leadership is currently the most frequently adopted school leadership theory internationally [5,6] and it appears in policy documents worldwide [1]. Yet no empirical study in the last decade has investigated the impact that distributed leadership policy has on leadership practice in post-primary schools. This review reveals some ambiguity, challenges and the potential for increased workload and stress as a result of uncritical implementation. These issues warrant further consideration and research.

\subsubsection{Examination of the Influence of Distributed Leadership on Teacher and Leader} Well-Being

The third recommendation for future research pertains to investigation of the influence of distributed leadership on teacher and leader well-being. The management style of a school, defined as the distinctive way in which an organisation makes decisions and discharges various functions [83], as well as the actions of administrators, can significantly affect teachers' well-being [84]. This link, later referenced by Prilleltensky, et al. [85], has not been addressed in relation to a distributed leadership management style in post-primary schools. Distributed leadership has been critiqued for creating increased workload and stress among school staff [16,86-88], yet this remains under-interrogated in the literature. It would be of benefit to examine teacher and leader well-being and stress levels in schools where distributed leadership is implemented.

\subsubsection{Exploration of Distributed Leadership in Relation to Female Leadership}

The fourth recommendation for future research is a study exploring the relationship between female leadership and distributed leadership. Female leadership is a topic that warrants consideration as a discrepancy has been reported between the percentage of females in the teaching profession in comparison with those in principal positions [61]. Within the literature reviewed, only $5.1 \%$ of studies investigated female leadership with 
regard to distributed leadership, one of which found that women's scores on distributed leadership were high [64]. This would further clarify the relationship between female leadership and distributed leadership, and further investigate if this has any impact on the number of female-led schools.

\subsubsection{Investigation of Teachers' and Leaders' Perceptions of Distributed Leadership}

The final recommendation for future research pertains to the need for studies investigating teachers' and leaders' perceptions of distributed leadership. While four articles $(10.2 \%, N=4)$, outlined secondary aims to identify teachers' and school leaders' perceptions of distributed leadership, no study in this review deemed participants' perceptions of distributed leadership as the focus of the research paper. Participants' perceptions were simply studied as an additional objective rather than the overall focus. As outlined in the review, there are discrepancies among participants' perceptions of distributed leadership. It is unclear how significant these discrepancies are, if they vary between teachers and school leaders, or if they potentially have a significant impact on data collection and analysis. It is also unclear if an accurate perception of distributed leadership among staff enables more effective distributed leadership, or if differences in perceptions inhibit its effect. This is a distinct gap in the literature that needs to be addressed to further inform distributed leadership practice in schools as well as the rigour of distributed leadership research.

\section{Conclusions}

Research on distributed leadership in schools has become more prevalent in recent times [7]. It has been studied using various methodologies, in various contexts with various constructs. However, this accumulation of research is not without its limitations. Over the past 10 years, distributed leadership research, conducted in post-primary schools, has rarely framed the study in a given context, and has not fully considered the influence of powerful factors such as school culture and national policy. Researchers have drawn conclusions as to distributed leadership and organisational commitment and school improvement; however, these conclusions require broader replication so as to be able to explore the construct's transferability, applicability and value. There remains lack of consensus in the literature on a single definition of distributed leadership. This lack of consensus serves only to give rise to the critiques of education research in general and of educational leadership research specifically. Given the weight that is now placed on distributed leadership internationally and its pre-eminence in many national education policies, it is timely that the body of knowledge is expanded in a rigorous and coherent manner. Distributed leadership is not leaving the educational stage any time soon. Differing and varied understandings are likely to lead to the development of policy that is based on a loosely coupled conceptualisation. Future research is recommended that will influence 'construct clean up' of this now pivotal concept in school leadership in order for distributed leadership to flourish, and in order to influence the development of distributed leadership policy in a meaningful and rigorous manner.

Author Contributions: This paper is the result of a genuine collaborative engagement between all authors based on core ethical principles of partnership and empowerment. Contributions to the paper were as follows, identified by author initials. Conceptualization, N.H., A.F. and P.M.M.; methodology designed by N.H., A.F. and P.M.M.; literature searches, N.H.; screening, N.H. and P.M.M.; resources, N.H., A.F. and P.M.M.; data curation, N.H. and A.F.; writing-original draft preparation, N.H. and A.F.; writing-review and editing, N.H., A.F. and P.M.M.; visualization, N.H., A.F. and P.M.M.; supervision, A.F. and P.M.M.; project administration, N.H. All authors have read and agreed to the published version of the manuscript.

Funding: This research was funded by Irish Research Council, grant number GOIPG/2021/1071.

Acknowledgments: The authors wish to thank those within the authors' institution for their support, as well as the Irish Research Council for funding this project.

Conflicts of Interest: The authors declare no conflict of interest. 


\section{Appendix A \\ Sample Search String from the Education Source Database}

Note: "AB" = Abstract, "TI" = Title, "DE" = Heading or Keyword.

DE "Educational leadership" OR AB (education and leader*) OR TI (education and leader*) AND AB (distributed leadership or distributive leadership) OR TI (distributed leadership or distributive leadership) AND AB (perceptions or attitudes or opinion or experience or view or reflection or beliefs) OR TI (perceptions or attitudes or opinion or experience or view or reflection or beliefs) AND (DE "Secondary schools" OR DE "High schools" OR DE “Junior high schools" OR DE “Middle schools" OR DE “Secondary modern schools (Great Britain)" OR DE “Secondary education") OR AB (post primary schools or post-primary schools or postprimary schools or secondary schools or high schools or middle schools or junior high schools) OR TI (post primary schools or post-primary schools or postprimary schools or secondary schools or high schools or middle schools or junior high schools) AND (((DE "School administrators" OR DE "Assistant school principals" OR DE "High school principals" OR DE “Junior high school principals" OR DE "Middle school principals" OR DE “Teachers" OR DE "High school teachers" OR DE "Junior high school teachers" OR DE "Middle school teachers" OR DE "Private school teachers" OR DE "Public school teachers" OR DE "Secondary school teachers" OR DE "School principals") OR (DE "School principals")) OR (DE "High school department heads")) OR AB (school principals or principals OR school leaders OR vice principals OR vice-principals OR deputy principals of assistant principals OR headmaster OR head master OR headmistress OR head mistress OR school administrators OR teachers OR school teachers OR high school teachers OR schoolteachers OR secondary school teachers OR junior high school teachers OR middle school teachers OR post-primary school teachers OR postprimary school teachers OR post primary school teachers OR educators) OR TI (school principals OR principals OR school leaders OR vice principals OR vice-principals OR deputy principals of assistant principals OR headmaster OR head master OR headmistress OR head mistress OR school administrators OR teachers OR school teachers OR high school teachers OR schoolteachers OR secondary school teachers OR junior high school teachers OR middle school teachers OR post-primary school teachers OR postprimary school teachers OR post primary school teachers OR educators)

Note: "AB" = Abstract, "TI" = Title, "DE" = Heading or Keyword.

\section{References}

1. Harris, A. Distributed leadership: Implications for the role of the principal. J. Manag. Dev. 2011, 31, 7-17. [CrossRef]

2. Young, J.T. Administrative Centralization and Decentralization in France. Ann. Am. Acad. Political Soc. Sci. 1898, 11, 24-43. [CrossRef]

3. Gronn, P. Distributed leadership. In Second International Handbook of Educational Leadership and Administration; Springer: Dordrecht, The Netherlands, 2002; pp. 653-696.

4. Harris, A. Distributed leadership: Friend or foe? Educ. Manag. Adm. Leadersh. 2013, 41, 545-554. [CrossRef]

5. Wenner, J.A.; Campbell, T. The theoretical and empirical basis of teacher leadership: A review of the literature. Rev. Educ. Res. 2017, 87, 134-171. [CrossRef]

6. Wang, Y. The panorama of the last decade's theoretical groundings of educational leadership research: A concept co-occurrence network analysis. Educ. Adm. Q. 2018, 54, 327-365. [CrossRef]

7. Youngs, H. Distributed Leadership. In Oxford Research Encyclopedia of Education; Oxford University Press: Oxford, UK, 2020.

8. Gronn, P. Distributed properties: A new architecture for leadership. Educ. Manag. Adm. 2000, 28, 317-338. [CrossRef]

9. Bolden, R.; Petrov, G.; Gosling, J. Distributed Leadership in Higher Education: Rhetoric and Reality. SAGE J. 2009, 37, 257-277. [CrossRef]

10. Gronn, P. The New Work of Educational Leaders: Changing Leadership Practice in an Era of School Reform; Sage: Thousand Oaks, CA, USA, 2003.

11. Bennett, N.; Wise, C.; Woods, P.A.; Harvey, J.A. Distributed Leadership:A Review of Literature; National College for School Leadership: Notthingham, UK, 2003; pp. 1-57.

12. Diamond, J.B.; Spillane, J.P. School leadership and management from a distributed perspective: A 2016 retrospective and prospective. Manag. Educ. 2016, 30, 147-154. [CrossRef]

13. Harris, A. Distributed leadership: Conceptual confusion and empirical reticence. Int. J. Leadersh. Educ. 2007, 10, 315-325. [CrossRef] 
14. Elmore, R.F. Building a New Structure for School Leadership; Albert Shanker Institute: Washington, DC, USA, 2000.

15. Spillane, J.P. Leadership and learning: Conceptualizing relations between school administrative practice and instructional practice. In How School Leaders Contribute to Student Success; Springer: Berlin/Heidelberg, Germany, 2017; pp. $49-67$.

16. Mayrowetz, D. Making sense of distributed leadership: Exploring the multiple usages of the concept in the field. Educ. Adm. $Q$. 2008, 44, 424-435. [CrossRef]

17. Harris, A. Distributed leadership: What we know. In Distributed Leadership; Springer: Berlin/Heidelberg, Germany, 2009; pp. 11-21.

18. Spillane, J.P. Distributed leadership. Educ. Forum 2005, 69, 143-150. [CrossRef]

19. Fitzsimons, D.; James, K.T.; Denyer, D. Alternative approaches for studying shared and distributed leadership. Int. J. Manag. Rev. 2011, 13, 313-328. [CrossRef]

20. Harris, A. Distributed leadership and school improvement: Leading or misleading? Educ. Manag. Adm. Leadersh. 2004, 32, 11-24. [CrossRef]

21. Spillane, J.P.; Halverson, R.; Diamond, J.B. Investigating school leadership practice: A distributed perspective. Educ. Res. 2001, 30, 23-28. [CrossRef]

22. Hallinger, P.; Heck, R.H. Distributed leadership in schools: Does system policy make a difference? In Distributed Leadership Springer: Dordrecht, The Netherlands, 2009; pp. 101-117.

23. Louis, K.S.; Mayrowetz, D.; Smiley, M.; Murphy, J. The role of sensemaking and trust in developing distributed leadership. In Distributed Leadership; Springer: Dordrecht, The Netherlands, 2009; pp. 157-180.

24. Woods, P.A.; Bennett, N.; Harvey, J.A.; Wise, C. Variabilities and dualities in distributed leadership: Findings from a systematic literature review. Educ. Manag. Adm. Leadersh. 2004, 32, 439-457. [CrossRef]

25. Edwards, G. Concepts of community: A framework for contextualizing distributed leadership. Int. J. Manag. Rev. 2011, 13, 301-312. [CrossRef]

26. Thorpe, R.; Gold, J.; Lawler, J. Locating distributed leadership. Int. J. Manag. Rev. 2011, 13, 239-250. [CrossRef]

27. Bolden, R. Distributed leadership in organizations: A review of theory and research. Int. J. Manag. Rev. 2011, 13, 251-269. [CrossRef]

28. Youngs, H. (Un) Critical times? Situating distributed leadership in the field. J. Educ. Adm. Hist. 2009, 41, 377-389. [CrossRef]

29. Crawford, M. Solo and distributed leadership: Definitions and dilemmas. Educ. Manag. Adm. Leadersh. 2012, 40, 610-620. [CrossRef]

30. Hairon, S.; Goh, J.W. Pursuing the elusive construct of distributed leadership: Is the search over? Educ. Manag. Adm. Leadersh. 2015, 43, 693-718. [CrossRef]

31. Tian, M.; Risku, M.; Collin, K. A meta-analysis of distributed leadership from 2002 to 2013: Theory development, empirical evidence and future research focus. Educ. Manag. Adm. Leadersh. 2016, 44, 146-164. [CrossRef]

32. Feng, Y.; Hao, B.; Iles, P.; Bown, N. Rethinking distributed leadership: Dimensions, antecedents and team effectiveness. Leadersh. Organ. Dev. J. 2017, 38, 284-302. [CrossRef]

33. Sivri, H.; Beycioğlu, K. A Review of Empirical Research on Distributed Leadership at Schools. Educ. Adm. Theory Pract. 2017, 23, 135-163. [CrossRef]

34. Gunter, H.; Hall, D.; Bragg, J. Distributed leadership: A study in knowledge production. Educ. Manag. Adm. Leadersh. 2013, 41, 555-580. [CrossRef]

35. Hartley, D. Paradigms: How far does research in distributed leadership 'stretch'? Educ. Manag. Adm. Leadersh. 2010, 38, 271-285. [CrossRef]

36. Munn, Z.; Peters, M.D.; Stern, C.; Tufanaru, C.; McArthur, A.; Aromataris, E. Systematic review or scoping review? Guidance for authors when choosing between a systematic or scoping review approach. BMC Med. Res. Methodol. 2018, 18, 143. [CrossRef]

37. Levac, D.; Colquhoun, H.; O'Brien, K.K. Scoping studies: Advancing the methodology. Implement. Sci. 2010, 5, 1-9. [CrossRef]

38. Arksey, H.; O'Malley, L. Scoping studies: Towards a methodological framework. Int. J. Soc. Res. Methodol. 2005, 8, 19-32. [CrossRef]

39. Colquhoun, H.L.; Levac, D.; O’Brien, K.K.; Straus, S.; Tricco, A.C.; Perrier, L.; Kastner, M.; Moher, D. Scoping reviews: Time for clarity in definition, methods, and reporting. J. Clin. Epidemiol. 2014, 67, 1291-1294. [CrossRef]

40. Sucharew, H.; Macaluso, M. Methods for Research Evidence Synthesis: The Scoping Review Approach. J. Hosp. Med. 2019, 14, 416-418. [CrossRef] [PubMed]

41. Stern, C.; Jordan, Z.; McArthur, A. Developing the review question and inclusion criteria. AJN Am. J. Nurs. 2014, 114, 53-56. [CrossRef] [PubMed]

42. Fink, A. Conducting Research Literature Reviews: From the Internet to Paper; Sage Publications: Thousand Oaks, CA, USA, 2019.

43. Haddaway, N.R.; Collins, A.M.; Coughlin, D.; Kirk, S. The role of Google Scholar in evidence reviews and its applicability to grey literature searching. PLoS ONE 2015, 10, e0138237. [CrossRef] [PubMed]

44. Cronin, P.; Ryan, F.; Coughlan, M. Undertaking a literature review: A step-by-step approach. Br. J. Nurs. 2008, 17, 38-43. [CrossRef]

45. Kitchenham, B. Procedures for Performing Systematic Reviews; Keele University: Keele, UK, 2004.

46. Daudt, H.M.; Van Mossel, C.; Scott, S.J. Enhancing the scoping study methodology: A large, inter-professional team's experience with Arksey and O'Malley's framework. BMC Med. Res. Methodol. 2013, 13, 48. [CrossRef] 
47. Crowe, M. Crowe Critical Appraisal Tool (CCAT) User Guide; Conchra House: Scotland, UK, 2013.

48. Tricco, A.C.; Lillie, E.; Zarin, W.; O’Brien, K.K.; Colquhoun, H.; Levac, D.; Moher, D.; Peters, M.D.; Horsley, T.; Weeks, L. PRISMA extension for scoping reviews (PRISMA-ScR): Checklist and explanation. Ann. Intern. Med. 2018, 169, 467-473. [CrossRef]

49. Ritchie, J.; Spencer, L. Qualitative data analysis for applied policy research. In Analyzing Qualitative Data; Routledge: London, UK, 2002; pp. 187-208.

50. Mowday, R.T.; Steers, R.M.; Porter, L.W. The measurement of organizational commitment. J. Vocat. Behav. 1979, 14, $224-247$. [CrossRef]

51. Devos, G.; Tuytens, M.; Hulpia, H. Teachers' organizational commitment: Examining the mediating effects of distributed leadership. Am. J. Educ. 2014, 120, 205-231. [CrossRef]

52. Hulpia, H.; Devos, G.; Van Keer, H. The Influence of Distributed Leadership on Teachers' Organizational Commitment: A Multilevel Approach. J. Educ. Res. 2009, 103, 40-52. [CrossRef]

53. Hulpia, H.; Devos, G. How distributed leadership can make a difference in teachers' organizational commitment? A qualitative study. Teach. Teach. Educ. 2010, 26, 565-575. [CrossRef]

54. Hulpia, H.; Devos, G.; Rosseel, Y. The relationship between the perception of distributed leadership in secondary schools and teachers' and teacher leaders' job satisfaction and organizational commitment. Sch. Eff. Sch. Improv. 2009, 20, 291-317. [CrossRef]

55. Hulpia, H.; Devos, G.; Rosseel, Y.; Vlerick, P. Dimensions of distributed leadership and the impact on teachers' organizational commitment: A study in secondary education. J. Appl. Soc. Psychol. 2012, 42, 1745-1784. [CrossRef]

56. Hulpia, H.; Devos, G.; Van Keer, H. The Relation Between School Leadership From a Distributed Perspective and Teachers' Organizational Commitment: Examining the Source of the Leadership Function. Educ. Adm. Q. 2011, 47, 728-771. [CrossRef]

57. Bird, S.N. Examining Middle Management Perspectives on Distributed Leadership: A Case Study of an Independent School. Ph.D. Thesis, University of Warwick, Coventry, UK, 2016.

58. Dampson, D.G.; Havor, F.M.; Laryea, P. Distributed Leadership an Instrument for School Improvement: The Study of Public Senior High Schools in Ghana. J. Educ. E-Learn. Res. 2018, 5, 79-85. [CrossRef]

59. Kelley, C.; Dikkers, S. Framing feedback for school improvement around distributed leadership. Educ. Adm. Q. 2016, 52, 392-422 [CrossRef]

60. Obadara, O.E. Relationship between distributed leadership and sustainable school improvement. Int. J. Educ. Sci. 2013, 5, 69-74.

61. OECD. Education at a Glance 2016; OECD: Paris, France, 2016.

62. Martínez, M.M.; Molina-López, M.M.; de Cabo, R.M. Explaining the gender gap in school principalship: A tale of two sides. Educ. Manag. Adm. Leadersh. 2021, 49, 863-882. [CrossRef]

63. Alyami, R.; Floyd, A. Female School Leaders' Perceptions and Experiences of Decentralisation and Distributed Leadership in the Tatweer System in Saudi Arabia. Educ. Sci. 2019, 9, 25. [CrossRef]

64. Marczynski, J.C.; Gates, G.S. Women secondary principals in Texas 1998 and 2011: Movement toward equity. J. Educ. Adm. 2013, 51, 705-727. [CrossRef]

65. Spillane, J.P. Distributed Leadership; Jossey-Bass: San Francisco, CA, USA, 2006.

66. Sesky, J. A Story of Distributed Leadership at a Turnaround High School: Identifying Settings and Practices. Ph.D. Thesis, University of California, Los Angeles, CA, USA, 2014.

67. Kwinda, A.A. Exploring Teachers' Perceptions of Distributed Leadership Practices in Selected Secondary Schools within Gauteng Province; University of Johannesburg: Johannesburg, South Africa, 2012.

68. O'Donovan, M. The challenges of distributing leadership in Irish post-primary schools. Int. Electron. J. Elem. Educ. 2017, 8, 243-266.

69. Tian, M. Distributed Leadership in Finnish and Shanghai Schools; Jyväskylä Studies in Education, Psychology and Social Research; University of Jyväskylä: Jyväskylä, Finland, 2016.

70. Humphreys, E. Distributed Leadership and Its Impact on Teaching and Learning. Ph.D. Thesis, National University of Ireland, Maynooth, Ireland, 2010.

71. Hulpia, H.; Devos, G. Exploring the link between distributed leadership and job satisfaction of school leaders. Educ. Stud. 2009, 35, 153-171. [CrossRef]

72. Hulpia, H.; Devos, G.; Rosseel, Y. Development and validation of scores on the distributed leadership inventory. Educ. Psychol. Meas. 2009, 69, 1013-1034. [CrossRef]

73. Harris, A. Teacher leadership as distributed leadership: Heresy, fantasy or possibility? Sch. Leadersh. Manag. 2003, 23, 313-324. [CrossRef]

74. Lumby, J. Distributed leadership in colleges: Leading or misleading? Educ. Manag. Adm. 2003, 31, 283-293. [CrossRef]

75. Knight, P.; Trowler, P. Departmental Leadership in Higher Education; Open University Press: Buckigham, UK, 2001.

76. Murphy, J.; Smylie, M.; Mayrowetz, D.; Louis, K.S. The role of the principal in fostering the development of distributed leadership. Sch. Leadersh. Manag. 2009, 29, 181-214. [CrossRef]

77. Hasanvand, M.M.; Zeinabadi, H.R.; Shomami, M.A. The study of relationship between distributed leadership and principals' self-efficacy in high schools of Iran. Int. J. Learn. Dev. 2013, 3, 92-100. [CrossRef]

78. Aliakbari, M.; Sadeghi, A. Iranian teachers' perceptions of teacher leadership practices in schools. Educ. Manag. Adm. Leadersh. 2014, 42, 576-592. [CrossRef] 
79. Chan, D. So why ask me? Are self-report data really that bad. In Statistical and Methodological Myths and Urban Legends: Doctrine, Verity and Fable in the Organizational and Social Sciences; Taylor \& Francis Group: New York, NY, USA, 2009; pp. 309-336.

80. Salahuddin, A.N.M. Perceptions of Effective Leadership in Bangladesh Secondary Schools: Moving towards Distributed Leadership? Master' Thesis, University of Canterbury, Christchurch, New Zealand, 2011.

81. Peterson, K.D.; Deal, T.E. How leaders influence the culture of schools. Educ. Leadersh. 1998, 56, 28-31.

82. Hinde, E.R. School culture and change: An examination of the effects of school culture on the process of change. Essays Educ. 2004, 12, 1-12.

83. Khandwalla, P.N. Effective Management Styles: An Indian Study; Indian Institute of Management Ahmedabad, Research and Publication Department: Ahmedabad, India, 1995.

84. Dworkin, A.G. Teacher Burnout in the Public Schools: Structural Causes and Consequences for Children; Suny Press: Albany, NY, USA, 1987.

85. Prilleltensky, I.; Neff, M.; Bessell, A. Teacher stress: What it is, why it's important, how it can be alleviated. Theory Pract. 2016, 55, 104-111. [CrossRef]

86. Liontos, L.B.; Lashway, L. Shared Decision-Making. In School Leadership: Handbook for Excellence; Smith, S.C., Piele, P.K., Eds.; ERIC Clearinghouse on Educational Management (University of Oregon, United States of America): Eugene, OR, USA, 1997; pp. 226-250.

87. Harris, A. Distributed School Leadership: Developing Tomorrow's Leaders; Routledge: London, UK, 2013.

88. Timperley, H.S. Distributed leadership: Developing theory from practice. J. Curric. Stud. 2005, 37, 395-420. [CrossRef] 